\title{
Crime, Controversy and the Comments Section: Discussing archaeological looting, trafficking, and the illicit antiquities trade online
}

\section{Meg Lambert and Donna Yates}

Cite this as: Lambert, M., Yates, D., (2015). Crime, Controversy and the Comments Section: Discussing archaeological looting, trafficking, and the illicit antiquities trade online, Internet Archaeology 39. http://dx.doi.org/10.11141/ia.39.6

\section{Introduction}

Academic blogging has gained popularity in recent years as researchers, along with the rest of the Internet-connected world, have explored and expanded upon the opportunities provided by the world wide web. This natural curiosity has recently been coupled with a push to engage by higher powers within university settings who believe in the efficacy of blogging as an educational tool. Much of the practical discussion surrounding blogging asks how academic blogs are being used, what audience is being reached, what impacts can be noted, and how it may contribute to researchers' careers in terms of investment and return on time and resources. Few of these discussions focus on the challenges inherent within a specific form of blogging on a specific topic.

The illicit looting, theft, and trafficking of cultural and archaeological objects has been a concern and source of study among academics, particularly archaeologists, since the mid-20th century. However, social media of the past decade has played a critical role in engaging countless numbers of actors against the illicit trade, disseminating data that might otherwise go unnoticed or unstudied, and sharing information in real time on issues such as conflict looting, illicit museum acquisitions, and landmark repatriation cases. This formerly obscure and neglected issue now routinely makes the front page of major newspapers. Blogs and social media websites such as Twitter have undoubtedly played a role in the 
rapid evolution of this emerging field. However, unique issues and challenges that are rarely discussed accompany the advantages to blogging in this arena.

Bloggers from each field of study navigate a complex web of issues when reaching out to and engaging with the public, disseminating information, and managing one's identity and CV as a professional. Beyond concerns about tone, content, and accessibility, those of us who engage in social media must also consider the implications of our actions. These issues are compounded when the blogger is writing about crime, criminals, and controversial topics. There is both professional and disciplinary danger in being blind-sided by major accusations such as copyright infringement or defamation. In very rare but no less serious cases, one may even deal with threats.

We believe these controversial topics are best approached through clear and open public fora. The following will present our understanding of the challenges involved in academic blogging, our individual experiences building and maintaining two popular blogs on the illicit antiquities trade, a contrasting experience building the Trafficking Culture website and its Encyclopedia, and finally our recommendations for bloggers, readers, and academic institutions involved in the push to engage in academic blogging.

\section{Background}

\subsection{Push to engage}

In recent years, there has been a strong push for postgraduates, researchers, and lecturers in social, political, and STEM (science, technology, engineering, and mathematics) sciences to become so-called 'engaged academics'. As employees of institutions that may be publically funded, and as educators first and foremost, there is a rising obligation to present findings to a wider audience in ways that are easy to access and understand. The development of the Internet as a locus of information sharing has drastically altered the academic game. Historically, this is an area where postgraduates and early-career researchers have held little ground. Traditional public engagement via public lectures, media interviews, and popular articles and books has most often been the territory of established academics. Such media have a rigid style in which academics may have little 
control over what and how information is presented.

The nuanced understanding of online communication that comes with the development of a digital world has allowed academics to stake out new territory in online public engagement. Academic blogging has been lauded as a means of clarifying ideas, exercising the ability to communicate succinctly and plainly, enhancing reputations, reaching estranged or wary audiences, approaching possible mentors and mentees, and overall demonstrating the social relevance of the academy through engagement. (Mewburn and Thomson 2013a) Increasingly, being an 'engaged academic' means being an 'online academic'. In addition to research, teaching, and publishing in peer-reviewed journals, academics now face funding bodies who require successful applicants to maintain information-sharing websites, employers who emphasise contributions to aggregate writing sites, and professional development workshops that focus on 'Media Training' and 'Public Engagement' to reach the maximum potential for online research exposure. Students are being introduced to blogging as undergraduates (Chong 2010), and postgraduates are increasingly encouraged to blog as a part of their introduction to academic work and to reflect on their experiences and struggles (Ward and West 2008).

\subsection{Impact}

Such efforts are supported by an immediate source of so-called 'quantifiable impact'. Rather than a simple citation count, blog analytics programs allow one to track information about the number of readers, average time spent on the site, and their geographic location. Twitter allows us watch a tweet be retweeted by our target stakeholders, power holders, and decision makers. Most importantly, all of this can be reduced to a series of charts to be reported to funding bodies and employers to demonstrate that we are worth our paycheques. Qualified impact may be measured in the form of networking and professional relationships, invitations to write or present for others, job offers, interest and correspondence from prospective students, and attention from major news media. While it is true that online engagement has no formal place within the assessment of academics within universities, our experience indicates that administrators are progressively taking note of publicity and numbers. 


\subsection{Finding voice and claiming ideas}

Academic blogging is often encouraged as a kind of writing exercise to refine individual voice, and as a platform for staking out one's research territory. This can be used both to establish one's presence as an expert, and to provide protection against being plagiarised by others. However, plagiarism among bloggers, although rarely discussed, may occur more often than is admitted or acknowledged. One example is was explored by The Guardian, in which PhD student Lucy Williams (2013) described having one of her blog posts plagiarised by numerous authors, her decision to partially shut down her blog in response to the silence she was met with by the perpetrators, and her resolve to continue blogging at some point despite the serious blow to her trust in the system.

\subsection{Gendered experiences}

Initially, one could easily assume that the field of illicit antiquities research is, like many other social and political science fields, dominated by privileged white males. While it may be the case that the majority of renowned and frequently cited experts are male, personal experience indicates that the greater number of emerging students and experts in this field are in fact female. This, however, is ill reflected in current social media. The authors of this paper are the only two female academics actively blogging about the illicit antiquities trade (at least in English), and are among a mere handful of female professionals visibly discussing these issues in news media.

Such disparate statistics are not unusual regarding the visibility of women scientists in social media. This issue was recently brought to major media attention by Emily Graslie (2013), writer and host of YouTube science series 'The Brain Scoop' and Chief Curiosity Correspondent at the Field Museum in Chicago. Graslie's video, 'Where My Ladies At?' questioned the noticeable lack of YouTube channels hosted by women in STEM fields, and demonstrated that the reason why might lie behind the blatantly sexist and bullying commentary Graslie has routinely fielded since launching 'The Brain Scoop'. Such issues are reflected in The Guardian's publication of one anonymous academic's lament that sexism is driving women out of science (Anonymous Academic 2014). The social sciences are similarly afflicted. A number of blogs have discussed the sexualisation, abuse, 
and discrimination that women scientists have experienced through engaging in social media (Mitchell 2013; De Lange 2012; Donald 2012).

\subsection{Discussion on blogging}

Much of the discussion around academic blogging takes place in articles and blogs themselves. The Guardian's Higher Education Network is one of the leading discussion forums on the role of academics in blogging, with articles covering reflections on different types and uses of academic blogging (Bessette 2011), the value of blogging in the process of academic publishing (Quinnell 2011), the importance of minority scholars' public visibility through engagement (Horn 2012), and reports on empirical research such as that by Thomson and Mewburn (2013). Similarly, the London School of Economics and Political Science runs 'The Impact Blog', which features a number of posts by scholars on the relationships between academic blogging and readership (Mewburn and Thomson 2013b), blogging as a supplement to scholarship (Maitzen 2013), and how academic blogging may shape intellectualism in the future (Davis 2013).

Few scholarly studies currently exist on the form, content, benefits, or efficacy of academic blogging. Ewins' empirical study (2005) on personal identity within and outside academic blogging identified a number of reasons academics blog, notably to communicate with peers, respond to books, articles, and dissertations in one place rather than in publications or letters, and to create personal archives over time that act as representations of an academic's body of work collected in one location. On the other hand, Gregg's (2009) study explores the differences between academic blogging as a professional with a secure position and blogging as a postdoctoral or junior faculty member with uncertain employment. She suggests that academic blogging can provide support for doctoral researchers who lack institutional support or supervision, offer a form of mentoring and job-seeking support, and provide a separate domain from parent institutions to foster academic community membership. Most recent is Inger Mewburn and Pat Thomson's study (2013a) on the reality behind the push to engage academics. Through content analysis of 100 academic blogs, Mewburn and Thomson, both bloggers themselves, determined that academics most commonly write about academic work conditions, policy contexts, and advice, rather than discussing 
their research. Such results, though limited to a small number of blogs in relation to the incalculable number of academic blogs in existence, challenge popular thinking in suggesting that audiences for such work are other higher education staff rather than non-academic individuals. Mewburn is in fact the author and editor of the acclaimed 'The Thesis Whisperer', which offers a guide to beginner academic bloggers using the results of her study with Thomson.

\subsection{The illicit antiquities trade in blogs}

Blogging has been a particularly important tool for illicit antiquities trade researchers over the last decade. While issues regarding the trade discussed in most blogs are derived from sources in the public domain, until recently there was no other place where this information could be collected, discussed, or analysed with the immediacy and accessibility that blogging allows. As a result, this small emerging field has become more tenacious and varied, as researchers, students, and other stakeholders have been able to collect and share information from sources that may be obscure, inaccessible to others owing to a paywall, or simply overlooked.

While the number of current bloggers may be quite low compared to the number of researchers that currently exist, all within this field pay close attention to blogs that act as main news sources on this topic and its many sub-fields. Many of these are led by archaeologists, such as Sam Hardy's Conflict Antiquities, David Gill's Looting Matters, and Paul Barford's Portable Antiquity Collecting and Heritage Issues. The Chasing Aphrodite blog by journalist Jason Felch has become one of the most relied upon news sources regarding museum acquisitions, court cases, and repatriations of looted objects, particularly from Europe and south-east Asia. Cultural Heritage Lawyer Rick St Hilaire's blog and Derek Fincham's Illicit Cultural Property provide legal perspectives on various cases and news items. Following these are a number of other blogs that provide personal and academic insight into on-going and past cases and the trade itself.

\section{Case Studies in Blogging}

The following describe our own experiences of creating and maintaining two blogs on the illicit antiquities trade that focus on crime and sociology rather than 
archaeology and activism, and how we have navigated through the above issues and challenges. In contrast, we discuss the creation of the Trafficking Culture website and its Encyclopedia, which provides a different tone and set of challenges.

\subsection{Donna}

\subsubsection{Motiivation}

I started Anonymous Swiss Collector in 2011 because I did not have a job and I wanted one. I had submitted my doctoral dissertation, had a lot of time on my hands, and felt that I lacked a clear public outlet to display my expertise on the topic of illicit antiquities, looting, and the trafficking of cultural property. I was not convinced that I was going to stay in academia and I realised that I would be consigned to obscurity if I kept quiet.

At that point I had another active blog, Grotesque Stone Idols, which was meant to be a space for unrelated heritage musings. I also had nearly a decade of experience with personal blogging via LiveJournal. Because of this experience with the medium, I sought to fill what I thought was a gap in what was being blogged about. The majority of illicit antiquities blogs, although well written and important in their own right, seemed to focus on commentary on various news items reported in the media. I wanted to move away from this model and focus on in-depth writing about specific topics within my expertise. In a sense, I wanted to create a window into my thinking as a researcher, not engage in activism per se. Furthermore I specifically wanted to promote Latin American research and issues, much of which never trickles into English.

\subsubsection{Experience}

Not so long after I started the blog I took a postdoctoral research position with the University of Glasgow's Trafficking Culture project. I felt this added weight to my blogged words as I was blogging about a topic that I was meant to be an expert in, and made it imperative that I was careful with my words and topics as it would appear as if I was representing my employer. Because of this, the blog became a bit neglected. Furthermore, I was hired to develop the Trafficking Culture project website, a writing-heavy task that left me drained. 
As the blog languished, viewership did not. It was ranked highly by Google and certain posts continued to draw viewers in large numbers, and turn up in academic spheres. Around this time I decided to turn off commenting on the blog. I realised that I am an academic, not a forum host, and that I do not need to provide a public medium for my ideas to be debated. I see the blog as a form of reporting ideas, broadcasting them even, that I pay to host. I am under no obligation to host arguments or opposing views. That said, I strongly encouraged readers to email me or interact with me via Twitter. Around the time I closed commenting, my Twitter follower count skyrocketed. Furthermore, no one but robots commented on my blog anyway. The days of LiveJournal style blog discussion and debate are, I think, mostly over.

As my reputation grew, I noticed an increase in the incidence of my words and thoughts being reused without proper citation or acknowledgement. In particular, my analysis of an auction of Latin American objects in 2013 was repeated, often with me cut out of the picture. This ranged from bloggers improperly citing other blogs (which had cited me) as their source of information, to a whole-host theft of my words posted without attribution on the website of an organisation that I do not support. While such practices are infuriating, I still believe that posting my research is positive: even if I am poorly cited, I have staked a public claim to certain lines of reasoning and those that matter know this.

Although I think my goals of a research-based, calm and collected blog were noble, as time has gone on I found myself engaging in the sort of blogging that I initially set out to avoid. I have used the blog simply to comment on news stories and, worse, I have displayed anger at times that I think is unbecoming. This coincided with a particularly hard time for me: several months of lonely solo fieldwork in Bolivia. I found it hard to moderate myself and even though my angry posts were very popular, I didn't like who I had become. A friend told me that if something is not elegant he will not do it, not even online. I feel that over time my blog lost its elegance and it has been a slow road to find it again.

\subsubsection{Where I am now}

I am yet again worried about job security: I have hit the halfway point of my fellowship and I know that I need to keep up a strong public profile if I want to be 
hired at the end of this. After several months of reflection I have determined that my blog is the best way to do this. It is well read and often shared via social media and I am shared along with it. It is also one of the most measurable mediums when it comes to the ever-elusive 'impact'. I can see how many people read my words and am able to communicate that in hard numbers to employers and funders.

Thus, Anonymous Swiss Collector has risen from the ashes. I put the blog through an intensive redesign. I have emphasised my expertise around professionalism by tying it to a CV, a good personal profile, and to my Twitter account and university profile. I have started a weekly feature where I post a collection of topical news in an effort to become a one-stop source on my topic. Finally I have filtered out the least elegant of previous posts and am watching my tone and content closely. I am determined to make this the blog I know it can be.

\subsection{Meg}

\subsubsection{Motivation}

My introduction to the illicit antiquities trade and related art and heritage issues began in 2009 with the discovery of Sharon Waxman's Loot (2008) and related investigative journalism. The topic dovetailed precisely with my then art history major, and I was increasingly determined that antiquities trafficking should be the focus of my undergraduate degree. Due to the generous but limited offerings of my small liberal arts college's library database, I relied heavily on the few illicit antiquities-focused blogs that existed for information and resources. These were generally archaeological in nature, harboured an activist tone, and catered to an audience already familiar with the issues. Unaware of any other resources that made the topic accessible for communities outside the academic sector, I saw an opportunity to carve a niche for myself in an emerging field. Marked by an activist zeal and a not-so-secret desire to be the next Sarah Vowell, I began Things You Can't Take Back (TYCTB) in January 2011.

\subsubsection{Experience}

My goal for TYCTB was to be a news blog where I could make current issues in cultural heritage more accessible for students of my generation. In an attempt to 
attract a young, hip audience, I adopted an irreverent vocabulary, unapologetically called out individuals and institutions on their actions, and highlighted student-specific opportunities such as internships, academic resources, and graduate programs. Over time, my goal for a news blog was impeded by my substantial undergraduate workload and the delay in my response to the news. Crafting a blog post took time as I attempted to construct my understanding of the issue at hand before beginning on the writing itself. By the time I knew what I wanted to say, the issue had ceased to be current, leading to general neglect during term time.

Despite my neglect, the blog garnered an unprecedented readership that presented me with brilliant opportunities and rarefied introductions to a field that would have otherwise been limited to scholars with more experience. This included bolstering my access to participants for my undergraduate thesis research, a job offer from my college to contribute to their nascent admissions blog (and subsequently to help manage and train new bloggers), invitations to speak at art crime-focused events, star-struck introductions to major experts, and ultimately my postgraduate application to the Trafficking Culture project. Later on, it also meant corresponding with students who were interested in Trafficking Culture research volunteer opportunities, or in applying to the Master of Research (MRes) in Criminology program that I undertook at the University of Glasgow.

I was fortunate that the community of male bloggers I joined was immediately and unwaveringly supportive. All criticism or negative commentary I received was never gender-based (as far as I could tell). Often, it had more to do with the controversial topic of my undergraduate thesis, the Smithsonian involvement in the display of the commercially salvaged Belitung ship, than anything else. However, experience revealed that while the illicit antiquities blogging community is generally free of sexist bullying or discrimination, my female colleagues and I are not exempt from the persistent sexual overtures of a small number of male colleagues at professional events.

The blog entered a downward spiral as I began my MRes in Criminology. On a practical level, the stress of transitioning to a new city and immersing myself in a new field left little time to reflect or report on news items. On a professional level, 
my previous irreverence proved both an advantage and a handicap during my postgraduate research. A particularly frank post about a certain institution's acquisitions earned me some friendships and a quote in the Ghanaian press, but inevitably became a source of nervousness and regret when I sought to interview curators from that museum for my dissertation. On a bigger philosophical level, my Masters program radically altered my perspective on the issues and how I wanted to approach them. Though half my undergraduate degree focused on anthropology, my immersion in sociology as a postgraduate challenged my perspectives on concepts of art, rights of ownership, definitions of crime, and rights of display. I embraced a perspective that became less occupied with shouting about awareness, and more interested in generating scientifically informed discourse on how socio-economic values of objects are constructed, how related crimes and social harms are defined by academic, economic, legal, and museum actors, and ultimately how behaviours and practices can be positively addressed. Initially, the paradigm shift in my perspective was difficult to communicate, particularly to myself. By the time my altered beliefs had coagulated in such a way that I could form coherent sentences, my blogging platform had become too buggy and inefficient, my domain name was lost, and I felt too distant from the blog to invest in overhauling it.

\subsubsection{Where II am now}

Over a year after my last post on TYCTB, I have begun the second year of my $\mathrm{PhD}$ with the Trafficking Culture project and recently launched a new blog. Developing my employability for the not-so-distant future has become a critical component of my day-to-day work. I see blogging as a valuable method of distinguishing one's self in a field that often discusses but rarely acts on engaging with audiences beyond the academic sector. Additionally, the uniquely interdisciplinary nature of my research area, which holds stakes in criminology, sociology, museum studies, human rights, and the sociology of academia itself, lends a sense of ethical obligation to disseminate my research among audiences that will be able to put it to good use sooner rather than later.

My next venture, Give and Take: A Sociological Response to the Illicit Antiquities Trade, has ditched the activist slant in order to provide a critical sociological 
perspective on issues relating to the illicit trafficking, collection, and exhibition of cultural objects, particularly West African cultural objects. To date, the blog itself is still $90 \%$ goals, ideas, and intentions, and only $10 \%$ functioning website. Though this new start is decidedly unhurried, it is far more calculated, informed, and self-aware than the verbal swashbuckling of my youth. Personal experience and research on impact, voice, legal issues, gender, and technological logistics will all contribute to establishing a solid foundation for this next venture. However, I am acutely aware of the issues facing me that are unique to this blog: writing about historical and current issues in West Africa as a white Western woman, discussing what is hopefully more sophisticated research as a postgraduate rather than as an undergraduate, and calling attention to issues without estranging myself from potential research participants. With these in mind, I am nonetheless excited to explore the sometimes unpleasant but always enlightening results of turning the analysis tables on ourselves as academics.

\subsection{Trafficking Culture}

In contrast to the blogging model of academic online engagement, in 2012 the Trafficking Culture website was launched as a knowledge exchange component of the European Research Council funded Trafficking Culture project at the University of Glasgow. Although the site was built with the blogging-associated content management system Wordpress, no blogging component was planned for Trafficking Culture. Working from the assumption that blogs, even those written by academics, are treated as a 'lesser' form of academic writing when it comes to academic citation, the Trafficking Culture team members developed what we call an Encyclopedia, which takes the place of what, on other sites, might be blog content.

The Encyclopedia, as it stands, contains over 100 case studies concerning the looting of archaeological sites and the illicit trafficking of cultural objects. These studies are written in accessible but formal language and they are academically referenced. Entries, which are mostly written by project team members, go through an internal review system before being sent to external reviewers, who largely look for potentially legally questionable language. Because the subject of antiquities trafficking inherently involves criminality, great care is taken around 
defamation law. Finally, the entry is placed on the site with the author credited. The Encyclopedia is updated as regularly as many academic blogs, and a feed of new entries is on the front page of the Trafficking Culture website.

It is clear that the Trafficking Culture Encyclopedia is approached very differently from blog entries, at least in our own blogging experience. The Encyclopedia is indexed by Google Scholar as academic articles, unlike our blog posts, and through this portal we are seeing that academics cite Encyclopedia entries in traditional journal articles often and more frequently than any of our blog posts. They are more frequently used as a source by the media as well, and tend to be an inspiration for academics to make formal research contact with us. That said, we believe that the articles are also being accessed by undergraduate students as well as the lay public.

The Trafficking Culture Encyclopedia is impersonal and presented within the frame of a well-known, funded academic project. The tone is serious, as is the content. What it lacks in 'personal voice', it makes up for in respectability, which is vital for the discussion of topics related to criminal behaviour. This is a model to experiment with.

\section{Recommendations}

Along the way, we have gathered certain wisdoms that we often wish had been shared with us at the beginnings of our blogging journeys. We've presented them here in brief for the benefit of experienced and beginner bloggers alike.

\section{1 To bloggers}

Reach out. Blogging has not just been a fancy line for our CVs, it has been an invaluable method of making connections that have lead to research opportunities, important professional contacts, and cherished friendships. Don't be afraid to introduce yourself to other bloggers (such as Donna did to Meg in 2011), or even to 'cold call' scholars and experts about your new endeavour (such as Meg did to every archaeology professor at every major US and UK university she could find after the launch of her first blog). Make people aware you're out there and ready to engage in a meaningful discourse. 
Don't saddle up your high horse. As we illustrated in our respective case studies, being too judgemental or aggressive with tone and content has caused more regret than satisfaction in our experience. As with everything else in life, it pays to separate the alleged facts from opinion calmly, and to refrain from calling people things you can't easily redact.

Check the libel laws in your country. At the extreme end of the judgement spectrum, your irreverence could get you slapped with a lawsuit. Double check the libel laws where you live to make sure that something you say won't result in legal complications.

\subsection{To readers}

Vet your blogs the way you would any other resource. Who is the blogger? How have they established their authority on the topic outside of the blogosphere? Who are they associated with? Have they involved themselves in the larger conversation, such as on Twitter, in major news sources, at conferences, or in peer-reviewed journals? Are they ever quoted or credited by other bloggers, scholars, and journalists for their insights and contributions? It can be difficult for newcomers to discern which voices are worth trusting and why. Additionally, the activist bent of some sources on this topic often attempt to create a sense of urgency by making claims that have not yet been scientifically proven. Examples include attributing the unproven $\$ 6$ billion figure to the annual revenue of antiquities trafficking, or claiming that antiquities trafficking has funded terrorism. Exercise typical precautions the way you would any other Internet, academic, or news source.

\subsection{To the system}

Invest in your researchers' presence online. Academics who have been writing for their peers for most of their career may not have the technological tools or web-culture literacy to write for popular audiences on this medium. We recommend employing experienced bloggers or social media experts to hold seminars and create guides to bring the expert voices on your payroll to a wider audience. Similarly, most social science academics do not have a working knowledge of HTML, CSS, or the ins and outs of website hosting. We believe it 
would be beneficial to offer such hosting and technical assistance through the university in the form of seminars, guides, and financial support.

\section{Acknowledgments}

The authors have received funding from the European Research Council under the European Union's Seventh Framework Programme (FP7/2007-2013) / ERC Grant agreement $n^{\circ} 283873$ GTICO, the Leverhulme Trust, and the Fulbright Program.

\section{PEER COMMENT}

\section{PREVIOUS NEXT CONTENTS ISSUE HOME}

(C) Author(s). Except where otherwise noted, content from this work may be used under the terms of the Creative Commons Attribution 3.0 Unported licence, which permits unrestricted use, distribution, and reproduction in any medium, provided that attribution to the author(s), the title of the work, the Internet Archaeology journal and the relevant URL/DOI is given.

$\underline{\text { University of York legal statements }}$

File last updated: Tue May 122015 